\title{
JURIMETRIA APLICADA AO PROCESSO DE RECUPERAÇÃO JUDICIAL PARA AFERIÇÃO DA ARQUITETURA DECISÓRIA DOS CREDORES
}

\author{
Alexandre Ferreira de Assumpção Alves \\ Gustavo Banho Licks
}

\section{Resumo}

Os objetivos da Lei ${ }^{\circ} 11.101$ pressupõem que os processos de recuperação judicial devem propiciar um ambiente de revitalização do devedor em crise através da união entre ele e seus credores. Por vezes, identifica-se que essa atmosfera não conseguiu ser alcançada, mas ainda assim os credores não deixaram de apoiar a devedora na votação do plano. Considerando que a tomada de decisão empresarial não deve se basear no altruísmo, aguça o interesse nesses casos. Apoiado no método indutivo, estudou-se cinco processos cujos resultados financeiros pioraram após a distribuição do pedido, em especial entre o processamento e a aprovação do plano.

Palavras Chaves: crise da empresa; recuperação judicial; assembleia de credores; plano de recuperação judicial; resultados financeiros.

\section{JURIMETRICS APPLIED TO JUDICIAL REORGANIZATION LAWSUIT TO ASSESS THE DECISION-MAKING ARCHITECTURE OF CREDITORS}

\begin{abstract}
:
It is assumed that judicial recovery processes should foster a revitalization environment for the business company in crisis through the union between creditors and debtors. At times, it is identified that this atmosphere has not been achieved, but still, creditors do not fail to support the debtor. Considering that business decision making should not be based on altruism, an interest in research was sparked. The study of five judicial recovery processes was conducted, whose financial results worsened after the distribution of the judicial recovery, specially between the granting of processing and the approval of creditors in assembly.
\end{abstract}

Key words: deepening insolvency; judicial recovery; committee of creditors; reorganization plan; financial performance

\section{1- INTRODUÇÃO}

O estudo da subsunção da autonomia da vontade do credor submetido à recuperação judicial é de suma importância. Pela Lei $n^{0}$ 11.101/ 2005 (LRF), compete ao credor interromper o agravamento da crise através da rejeição do plano em assembleia, que

\footnotetext{
* Advogado. Professor titular de Direito Empresarial na UFRJ e prof. associado na UERJ. Membro do PPGD da UERJ, linha de pesquisa Empresa e Atividades Econômicas.

*Advogado. Doutorado em Direito em curso na UERJ, linha de pesquisa Empresa e Atividades Econômicas.
} 
acarretará a decretação da falência, exceto se for apresentado e aprovado plano alternativo dos credores. Eventualmente, a decisão do credor pode apresentar aparente contradição, quanto opta por alongar o estado de crise indefinidamente ao apoiar devedores, cujas atividades empresárias se deterioraram durante o processo recuperacional. Além do espectro jurídico, a arquitetura decisória dos credores também pode ser investigada sob outros prismas.

Richard Posner (2010, p.59) explica que a Teoria do Direito baseado no Utilitarismo teria por premissa o entendimento de que a função do Direito seria a maximização da felicidade. Logo, "o valor moral de uma ação, conduta, instituição ou lei que deve ser julgada por sua eficácia na promoção da felicidade". No âmbito da recuperação, a "promoção da felicidade" para o credor tem íntima relação com a recuperação do crédito, ainda que a longo prazo. Sem esta esperança não vale a pena manter o devedor em recuperação, pois o cenário seria pior do que numa eventual decretação da falência. Pela concepção Consequencialista, também apoiada em análise econômica, o Direito deve ser analisado pelas diferentes alternativas e as consequências vinculadas a cada decisão por um critério de ponderação de valores (bom ou ruim, justo ou injusto, válido ou inválido) e tendo em vista os resultados que produz (POSNER: 2010, p.24 et seq.). Na assembleia de credores os votos devem ser proferidos de modo a ponderar as consequências dos efeitos da decisão tomada, ainda que por maioria. Os credores devem, por exemplo, decidir pela aprovação ou rejeição do plano e, ainda, sobre eventual plano alternativo. Cada decisão poderá ou não lhes trazer a promoção da felicidade, mas a ponderação sempre estará presente - manter ou não a empresa em funcionamento ou liquidá-la.

Outra perspectiva, pelos aplicadores da Análise Econômica do Direito, a análise das normas legais deve indicar de maximização do bem-estar social, promovendo a eficiência do Direito (POSNER, 2010, p.12). A noção de "bem-estar social" é aberta e adaptável ao momento e circunstâncias de tempo e espaço; todavia, na recuperação judicial quanto melhor for o êxito da implementação da medida maior será o "bem-estar social" proporcionado pela empresa. Com base nas técnicas de jurimetria, analisou-se a tomada de decisão dos credores em apoiar planos de recuperação judicial que, aparentemente, não teriam êxito. A jurimetria revelou-se importante pelo uso de estatísticas para prever resultados e oferecer conclusões nestas análises.

Utilizando o método indutivo, que parte da observação dos fatos para alcançar conclusões neles apoiadas, escolheu-se cinco processos que tramitaram nas Varas 
Empresariais da Comarca da cidade do Rio de Janeiro entre os anos de 2015 e 2018. A opção de processos nas Varas Empresariais justifica-se pelo fato dos juízes e promotores de justiça serem especializados, o que permite uma melhor comparação entre eles. O período de coleta das amostras fundamenta-se por serem processos maduros, que não sofreram com os efeitos da Emergência em Saúde Pública de Importância Internacional (ESPII) causada pelo COVID19, tampouco há um largo lapso temporal entre eles. Duas recuperações judiciais foram protocoladas em 2018, duas em 2017 e uma em 2015. Além de uma breve descrição dos processos, o estudo proposto demonstrou o agravamento da crise à época da assembleia, os prazos transcorridos entre o deferimento do processamento da recuperação e a aprovação do plano pelo credor, bem como o posicionamento dos credores em assembleia por classe, que não foi pela rejeição do plano a despeito do cenário desfavorável à manutenção da empresa.

\section{2- BREVE SÍNTESE DOS PROCESSOS ESCOLHIDOS PARA ANÁLISE}

A característica comum entre os cinco processos escolhidos é a deterioração dos resultados da atividade empresarial nos três anos que antecederam a distribuição do pedido de recuperação judicial. Além disto, observa-se em todos eles o agravamento da crise entre o deferimento do processamento e a aprovação do plano de recuperação judicial em assembleia. O primeiro processo ( $\mathrm{n}^{\mathrm{o}}$ 0409623-93.2015.8.19.0001) envolve a Civilport Engenharia Ltda. e Civilport Logistica e Locação de Equipamentos Ltda., tendo sido distribuído em 2015 para a $6^{\text {a }}$ Vara Empresarial. O segundo processo ( $\mathrm{n}^{\mathrm{o}}$ 0040930-62.2017.8.19.0001), que tem como parte a sociedade Brasil Supply S.A e outras duas sociedades empresárias, foi distribuído em 2015 para $5^{\mathrm{a}}$ Vara Empresarial. O terceiro processo ( $\mathrm{n}^{\mathrm{o}}$ 0310724-89.2017.8.19.0001) foi distribuído 2017 para a $1^{\text {a }}$ Vara Empresarial, sendo recuparanda a sociedade Arpoador Engenharia Ltda. O penúltimo processo estudado ( $\mathrm{n}^{\circ}$. 0141112-22.2018.8.19.0001) diz respeito à sociedade Companhia Federal de Fundição S.A. e foi distribuído para $4^{\mathrm{a}}$ Vara Empresarial em 2018. O último processo analisado ( $\left.n^{\circ} 0280230-13.2018 .8 .19 .0001\right)$, em que consta no polo ativo a sociedade Hotéis Othon S.A., tramita na $5^{\text {a }}$ Vara Empresarial desde 2018. A seguir serão apresentados breves dados sobre cada devedora, como lugar da sede, área de atuação, origem da crise, documentação apresentada ou analisada, andamento processual até da data da assembleia e votação do plano. 


\subsection{Civilport Engenharia Ltda. e Civilport Logística e Locação de Equipamentos Ltda.}

Civilport Engenharia Ltda. é uma sociedade limitada constituída em maio de 1986, com sede no centro da cidade do Rio de Janeiro-RJ, que tem por objeto as atividades de construção civil, projetos e consultoria. Civilport Logística e Locação de Equipamentos Ltda. foi constituída em fevereiro de 2014, com sede em Realengo, bairro da cidade do Rio de Janeiro, atuando com gestão bens móveis, logística e locação, assim como de recursos financeiros, próprios ou pertencentes a sociedades ligadas, controladas ou coligadas; locação de máquinas e equipamentos para a constrição, sem operador, dentre outras atividades descritas no objeto social relacionadas à construção civil. As recuperandas compõem o Grupo econômico Civilport, mas nao se identificou nos autos do processo a relação de controle entre as elas.

\subsubsection{Origem da crise}

A crise é fruto da recessão econômica brasileira e seus reflexos no setor da construção civil e infraestrutura, que diminuiu a demanda por serviços. $\mathrm{O}$ aumento do preço dos insumos, escassez de crédito e falta de liquidez no mercado prejudicaram as operações. Outro fundamento seria a execução de obra contratada com a Transnordestina Logística S.A. causado pela não liberação de áreas para as frentes de trabalho, atrasos no pagamento, amortizações incorretas nas medições, e o não reajustamento anual dos preços unitários do contrato.

\subsubsection{Documentação apresentada/ analisada}

As demonstrações financeiras dos exercícios de 2012, 2013 e 2014 foram extraídas dos documentos que instruíram a petição inicial e as informações financeiras durante o período processual (2015 e 2016) foram obtidas nos relatórios mensais do administrador judicial. No ano de 2012, o resultado líquido era positivo em R \$ 18.390.054,00, em 2013, o lucro apresentado era de $\mathrm{R} \$ 12.666 .805,00$, e, em 2014, de $\mathrm{R} \$ 3.143 .175,00$ (queda acentuada). Em 2015, contabilizou-se prejuízo no valor de R\$1.018.738,00 e, em 2016, também contabilizou-se resultado negativo de $\mathrm{R} \$ 9.447 .697,00$. 


\subsubsection{Andamento processual}

A petição inicial foi distribuída em 5 de outubro de 2015 e, em 21 de outubro do mesmo ano, publicou-se o deferimento do processamento. O plano de recuperação judicial foi apresentado pela requerente em 21 de janeiro de 2016 (fora do prazo de 60 dias previsto no art. 53 da Lei $\mathrm{n}^{\circ}$ 11.101) e votado em assembleia em 14 de outubro de 2016 (mais de 1 ano após o pedido), aprovando-o todas as classes de credores. A concessão da recuperação judicial foi publicada em 26 de outubro de 2016; todavia, houve agravo da decisão, mas posteriormente e mediante composição consensual de conflitos entre a recuperanda e a credora TLSA, confirmou-se a concessão da recuperação judicial em 3 de julho de 2017. A recuperação foi encerrada em 4 de dezembro de 2018.

\subsubsection{Votação do Plano de Recuperação Judicial}

A primeira convocação para realização da assembleia geral de credores foi marcada para 30 de setembro de 2016, não instalada por falta de quórum. O plano de recuperação judicial foi votado e aprovado em segunda convocação, instalada em 14 de outubro de 2016.

\subsection{Brasil Supply S.A., BSCO Navegação S.A. e BS Fluídos Ltda.}

Brasil Supply S.A., controladora das demais sociedads, é uma companhia constituída em junho de 2002, com sede no centro na cidade do Rio de Janeiro, para desenvolver a prestação de serviços logísticos de operações portuárias, de importação e exportação, armazenagem e movimentação de cargas, combustíveis, entre outras atividades similares. BSCO Navegação S.A. é uma companhia constituída em dezembro de 2007, com sede no centro da cidade do Rio de Janeiro, que se dedica a explorar o comércio marítimo de longo curso, cabotagem e fluvial no transporte de cargas em geral, bem como atuar na navegação de apoio portuário e exercer atividades complementares de armazenagem, logísticas e administração de embarcações. BS Fluídos Ltda. é uma sociedade constituída em janeiro de 2008, com sede na cidade de Anchieta - ES, que atua no beneficiamento e industrialização de produtos, gestão e destinação de resíduos, carga, descarga e armazenamento de mercadorias. 


\subsubsection{Origem da crise}

A queda do preço do barril de petróleo no mercado internacional e a Operação Lava Jato e seus efeitos para a Petrobras S/A, principal cliente, constituíram os principais fundamentos da crise. O Grupo Brasil Supply, embora não esteja envolvido de nenhuma forma na referida Operação, sofreu as consequências da insegurança política e econômica na cadeia produtiva de óleo e gás nacional; sofreu também com uma forte restrição de acesso ao crédito. Por fim, o estaleiro EISA, escolhido para a construção de quatro embarcações de apoio à plataformas, ajuizou ação de recuperação judicial em 2015 e teve suas atividades paralisadas por meses. Os atrasos daí decorrentes prejudicaram o cronograma de entrega de embarcações a Petrobras, gerando uma cadeia de graves consequências para as operações da Brasil Supply.

\subsubsection{Documentação apresentada/ analisada}

As três sociedades apresentaram balanço patrimonial e demonstrações de resultados dos exercícios de 2014, 2015 e 2016. As informações financeiras dos anos de 2017 e 2018 foram extraídas dos relatórios do administrador judicial. Em 2013 e 2014 foram contabilizados prejuízos de $\mathrm{R} \$ 41.796 .000,00$ e de $\mathrm{R} \$ 38.800 .000,00$, respectivamente (ligeira redução, mas ainda assim dados negativos). Em 2015, o resultado negativo encontrado foi de $\mathrm{R}$ \$ 63.835.000,00; em 2016, o prejuízo foi de $\mathrm{R} \$ 32.598 .000,00$, que aumentou para $\mathrm{R} \$$ 89.548.930,00 em 2017, e para R\$128.141.000,00, em 2018 (agravamento entre 2016 a 2018).

\subsubsection{Andamento processual}

A petição inicial foi distribuída em 17 de fevereiro de 2017 e o processamento deferido em 23 de fevereiro de 2017. O plano de recuperação judicial foi apresentado pelas requerentes em 12 de maio de 2017 (fora do prazo legal), sendo aprovado pelos credores em assembleia realizada em 22 de fevereiro de 2018, ou seja, 1 ano após o pedido. A concessão da recuperação judicial ocorreu em 20 de agosto de 2018 (6 meses após a deliberação da 
assembleia) e a sentença de encerramento da recuperação judicial foi publicada em 12 de novembro de 2020.

\subsubsection{Votação do Plano de Recuperação Judicial}

A assembleia geral de credores não foi instalada em primeira convocação, marcada para 30 de janeiro de 2018, por falta do quórum mínimo previsto no artigo $37, \S 2^{\circ}$, da Lei $\mathrm{n}^{\circ}$ 11.101/2005. A instalação se deu em segunda convocação realizada em 6 de fevereiro de 2018, e suspensa para continuidade no dia 22 de fevereiro de 2018. Ao retomar os trabalhos, os credores aprovaram o plano de recuperação judicial.

\subsection{Arpoador Engenharia Ltda.}

A sociedade em recuperação foi constituída em dezembro de 2002, com sede no centro da cidade do Rio de Janeiro, especializada em construção de embarcações de grande porte.

\subsubsection{Origem da crise}

Em razão da crise do setor de óleo e gás, seu principal cliente, BSCO Navegação S.A., requereu recuperação judicial, ocasionando a suspensão dos pagamentos de elevado valor devidos à Arpoador Engenharia Lida. O cliente pertence ao Grupo Brasil Supply, que prestava serviço para a Petrobras S.A, que reduziu a demanda pelos serviços.

\subsubsection{Documentação apresentada/ analisada}

A documentação contábil relacionada aos três exercícios anteriores ao processo (2014, 2015 e 2016) foi apresentada com a inicial. As demais demonstrações financeiras $(2017,2018$ e 2019) foram apresentadas ao longo do processo pelo administrador judicial. No ano de 2014

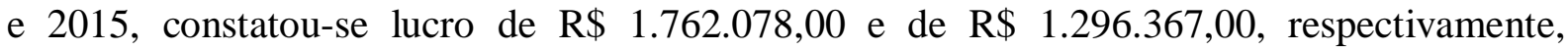
mantiveram-se positivos nos exercícios de 2016 e 2017, quando se apurou os resultados de R\$ 571.881,00 e de R\$ 848.282,00. Porém, nos exercícios de 2018 e 2019, os prejuízos totalizaram $\mathrm{R} \$ 237.360,00$ e $\mathrm{R} \$ 1.499 .932,00$ respectivamente (aumento de 531,9\%). 


\subsubsection{Andamento processual}

A petição inicial foi distribuída em 5 de dezembro de 2017 e o deferimento do processamento publicado em 10 de janeiro de 2018, sendo o plano de recuperação judicial apresentado em 15 de março de 2018 (fora do prazo legal). A assembleia geral de credores ocorreu em 26 de junho de 2019 (1 ano e 6 meses após o pedido), sendo o plano aprovado. Em 2 de julho de 2019, foi publicada a decisão de concessão da recuperação judicial e, em 7 de dezembro de 2020, foi instalada a assembleia geral de credores para votar alterações no plano. As modificações passaram pela análise de legalidade do juízo, sendo homologado.

\subsubsection{Votação do Plano de Recuperação Judicial}

A assembleia geral de credores foi instalada em primeira convocação no dia 10 de abril de 2019 e suspensa para continuação em 26 de junho 2019. Ao retomar os trabalhos da assembleia, os credores aprovaram o plano de recuperação judicial.

\subsection{Companhia Federal de Fundição S.A.}

A companhia foi constituída em agosto de 1985, com sede na Barra da Tijuca, bairro da cidade do Rio de Janeiro. A devedora, dentre outros objetos societários, projeta e fabrica maquinário, equipamentos, peças, acessórios e outros produtos, principalmente para o fabrico de celulose, papel e papelão.

\subsubsection{Origem da crise}

Os empresários do setor de mídia impressa, como jornais e livros, grandes consumidores de papel e celulose, vêm enfrentando significativa redução de demanda por seus produtos em virtude da concorrência com as mídias digitais e seus baixos custos de produção de conteúdo. Além disso, o segmento passou a disputar o mercado com pequenos concorrentes, que possuem custos inferiores. Para reverter o declínio das receitas, a Companhia Federal de Fundição S.A. buscou parceria com a Tetrapel Indústria e Comércio de 
Máquinas Ltda. Juntas, as sociedades empresárias constituíram as sociedades Advanced Metal Tecnologia Industrial e Serviços Ltda. e TMC Tecnologia Mecânica Continental Ltda, porém o investimento não teve o retorno pretendido e consumiu ainda mais os recursos da devedora. Para minimizar as perdas e gerar sinergia, as duas novas sociedades foram incorporadas pela devedora, mas também não se alcançou o resultado esperado.

\subsubsection{Documentação apresentada/ analisada}

As demonstrações financeiras dos exercícios de 2017, 2016 e 2015 foram apresentadas com a petição inicial. Os exercícios de 2018 e 2019 foram analisados com base nas informações apresentadas pelo administrador judicial (relatórios mensais). A recuperanda apresentou resultado negativo em todos os exercícios: em 2015 de R $\$ 326.431,52$; em 2016 de R\$ 65.073,23; em 2017 de R\$ 247.717,42; em 2018 de R\$ 360.376,91; em 2019 de R\$ $649.500,70$.

\subsubsection{Andamento processual}

A petição inicial foi distribuída em 15 de junho de 2018 e a publicação do deferimento do processamento em 10 de julho de 2018. O plano de recuperação judicial foi apresentado em 4 de outubro de 2018 (fora do prazo legal), sendo aprovado pelos credores em assembleia realizada no dia 5 de abril de 2019 (quase 9 meses após o pedido). A decisão de concessão da recuperação judicial foi publicada em 12 de julho de 2019 (3 meses após a deliberação).

\subsubsection{Votação do Plano de Recuperação Judicial}

A assembleia geral de credores, marcada para 29 de março de 2019, não foi instalada em primeira convocação por insuficiência de quórum previsto no artigo 37 , $\S 2^{\circ}$ da Lei $n^{\circ}$ 11.101/2005. A votação e aprovação do plano de recuperação judicial ocorreram em segunda convocação, realizada em 05 de abril de 2019.

\subsection{Hotéis Othon S.A. e otros.}


A recuperação judicial envolve três sociedades: (i) Hotéis Othon S.A., constituída em dezembro de 1965, com sede em Copacabana, bairro da cidade do Rio de Janeiro, com o objeto social de exploração da indústria hoteleira em qualquer de suas modalidades, (ii) HBBH - Empresa Brasileira de Novos Hotéis Ltda., constituída em maio de 2006, sediada no centro da cidade do Rio de Janeiro-RJ, com o mesmo objeto social e (iii) Othon Empreendimentos Hoteleiros S.A., constituída em abril de 1978, com sede em Campos dos Goytacazes-RJ, atuando na compra e venda de imóveis, bem como em participações societárias.

\subsubsection{Origem da crise}

Foram expressivos os investimentos feitos pelas devedoras para a modernização dos hotéis, visando a Copa do Mundo e os Jogos Olímpicos, porém houve uma forte e inesperada queda da demanda logo após os eventos, o que não permitiu o retorno do capital investido. A queda da demanda é atribuída à crise econômica nacional e, em especial, a do Estado do Rio de Janeiro. Também lista a petição inicial a crise do segmento de óleo e gás que contribuiu para manter uma taxa de ocupação mínima entre os períodos de alta demanda.

\subsubsection{Documentação apresentada/ analisada}

As análises de jurimetria contaram com as demonstrações financeiras que instruíram a petição inicial referentes aos exercícios de 2015, 2016 e 2017, bem como utilizou as informações financeiras apresentadas no relatório do administrador judicial para os exercícios de 2018 e 2019. A recuperanda apresentou prejuízo em todos os exercícios sob análise: em 2014, de R\$832.000,00; em 2015, de R $\$ 23.818 .000,00$; em 2016, de R 4.223.000,00; em 2017, de R\$ 40.155.000,00; no ano de 2018, de R\$ 94.746.000,00; em 2019, de R\$ 105.081.000,00. Houve expressivo prejuízo em 2016, 2.762\% maior do que ano anterior.

\subsubsection{Andamento processual}

A petição inicial foi distribuída em 27 de novembro de 2018 e a publicação do deferimento ocorreu em 28 de novembro de 2018. O plano de recuperação judicial foi 
apresentado de forma consolidada em 8 de fevereiro de 2019 (fora do prazo legal). Em 5 de julho de 2019, a devedora apresentou uma nova versão, aprovada pelos credores em assembleia em 5 de dezembro de 2019 (1 ano da data do pedido). Em 9 de julho de 2020, (8 meses depois) publicou-se a concessão da recuperação judicial.

\title{
2.5.4 Votação do Plano de Recuperação Judicial
}

A assembleia geral de credores foi instalada em primeira convocação no dia 22 de novembro de 2019 e suspensa para continuação no dia 5 de dezembro de 2019. O plano de recuperação judicial foi votado e aprovado nesse dia.

\section{JURIMETRIA APLICADA AO PROCESSO DE RECUPERAÇÃO JUDICIAL}

A Associação Brasileira de Jurimentria esclarece que "os avanços da computação possibilitaram uma nova forma de encarar as normas e a sua aplicação, que se baseia em dados e, consequentemente, em estatísticas. Por isso, ela pode ser genericamente definida como "a estatística aplicada do Direito" ${ }^{3}$. Luiz Fux (2019, p.15) complementa, argumentando que a "análise econômica faz uso da Estatística, o ramo da ciência que cuida da descrição de dados e das inferências que podem ser realizadas a partir deles". O autor acrescenta a importância dos testes empíricos que auxiliam a dar concretude à hipótese abstrata e o uso das ferramentas estatísticas aplicadas à tomada de decisão do credor em relação ao plano de recuperação judicial

\begin{abstract}
Além do raciocínio dedutivo ou teórico, a Economia também se vale do estudo indutivo ou empírico para testar as hipóteses construídas na teoria. Na verdade, o conhecimento científico apenas é produzido a partir da sequência iterativa de deduções fundamentadas em teorias e induções extraídas de fatos. O diálogo entre observação e ideias é o que permite refinar ou eliminar hipóteses cujas consequências não sejam confirmadas pelos fatos, exigindo a formulação de uma nova hipótese mais robusta. Noutras palavras, o teste empírico auxilia o cientista a realizar conclusões sobre a hipótese abstrata, que pode variar entre a necessidade de qualificação da proposição sob análise, a sua confirmação sob generalidade dos dados colhidos (Idem).
\end{abstract}

Corroborando com Luiz Fux, a Associação Brasileira de Jurimentria argumenta que a jurimetria enxerga "o Judiciário como um grande gerador de dados que descrevem o

\footnotetext{
${ }^{3}$ Disponível em: https://abj.org.br/conteudo/jurimetria/. Acesso em: 22 mar. 2021.
} 
funcionamento completo do sistema. Quando se faz jurimetria, estuda-se o Direito através das marcas que ele deixa na sociedade." 4 A entidade ressalta a importância da ausência de viés nas pesquisas baseadas em jurimetria para que não se crie um sofisma.

\begin{abstract}
Não há uma cartilha a ser serguida, apenas um conjunto de prinípios que deixam próximas todas as formas de jurimetria: [...]. A boa jurimetria deixará os dados contarem a história que for relevante para o tema em estudo, enquanto a má jurimetria não tomará o devido cuidado com a forma que analisam os dados e estará sujeita a conclusões inconsistentes. 5
\end{abstract}

Porém, as premissas aplicadas na pesquisa em tela não consideram que a jurimetria seja a única ferramenta para desvendar a aparente contradição de credores apoiando um processo recuperacional fadado ao fracasso. As pesquisas que fundamentam suas conclusões apenas em jurimetria correm o risco de perder a visão axiológica transversal do processo recuperacional. Logo, as análises a seguir são expostas com uma contribuição que devem ser objeto de outras pesquisas para se completarem, como a análise da racionalidade do voto.

\title{
3.1 Agravamento da crise após o processamento da recuperação judicial
}

Considerando que o "remédio" da recuperação judicial deva ser aplicado para as empresas sob crise de liquidez, os processos em que se identificou prejuízos acumulados durante o período do processamento até a realização da assembleia de credores - teriam sua crise agravada. Isto ficou patente no cotejo das demonstrações financeiras com os relatórios apresentados pelos administradores judiciais. Optou-se pelo método da análise gráfica do Resultado Líquido por ser uma "fotografia panorâmica", o que permite identificar uma tendência de melhora ou agravamento do estado de liquidez da devedora ${ }^{6}$.

\subsubsection{Civilport Engenharia Ltda. e outros}

\footnotetext{
${ }^{4}$ Ibid.

${ }^{5}$ Disponível em: https://abj.org.br/conteudo/jurimetria/. Acesso em: 22 mar. 2021.

${ }^{6}$ Para Tom Copeland, Tim Koller e Jack Murrin, "o primeiro passo na avaliação de uma empresa é a análise de seu desempenho histórico. Uma boa compreensão do desempenho passado da empresa proporciona uma perspectiva essencial para o desenvolvimento e avaliação de previsões quanto ao desempenho futuro" (COPELAND et al; 2002, p. 160).
} 
A documentação utilizada para o estudo foi somente da Civilport Engenharia Ltda, principal devedora. O resultado líquido dos anos de 2012 a 2014 foram coletados das demonstrações contábeis em anexo da petição inicial. Nos relatórios mensais do administrador judicial os dados obtidos foram para os anos de 2015 a 2016.

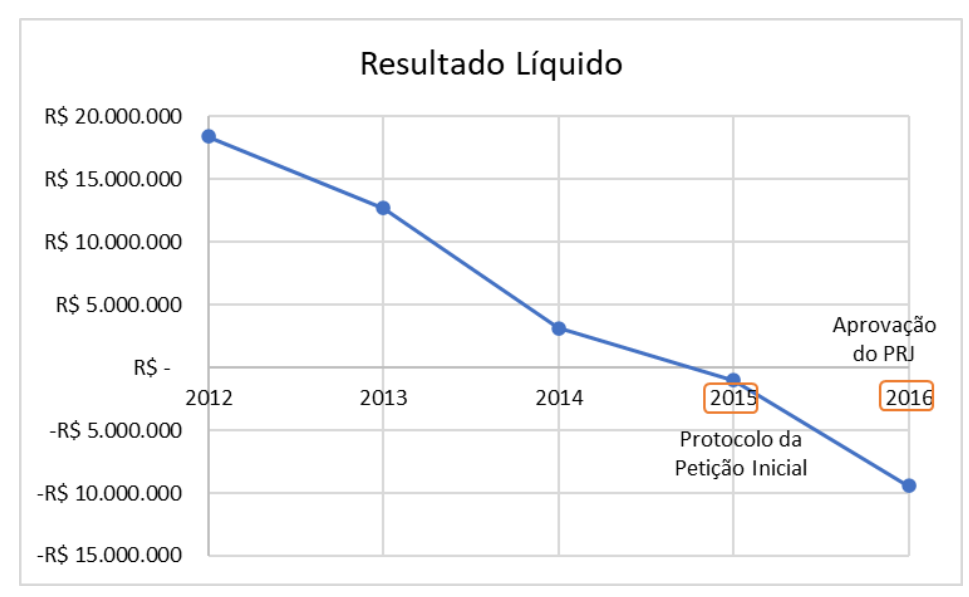

Figura 1. Civilport Engenharia Ltda. Elaboração própria.

No ano de 2013, houve queda de 31,12\% em comparação ao ano de 2012. Em 2014, houve queda de 75,19\% em relação ao anterior. Já em 2015, a queda foi de $132,41 \%$ em relação ao ano anterior. Em 2016, o prejuízo ficou maior e aumentou em 827,39\%. O gráfico evidencia uma constante piora dos resultados da devedora desde 2012. Entre 2015 e 2016, a sociedade apurou prejuízo e não houve melhora nos resultados mesmo com o processamento da recuperação e suspensão das execuções.

\subsubsection{Brasil Supply S.A. e outros}

As análises foram elaboradas com base nas demonstrações financeiras da Brasil Supply, controladora das demais, apresentadas na petição inicial e com base nos relatórios mensais do administrador judicial que foram juntados aos autos do processo. 


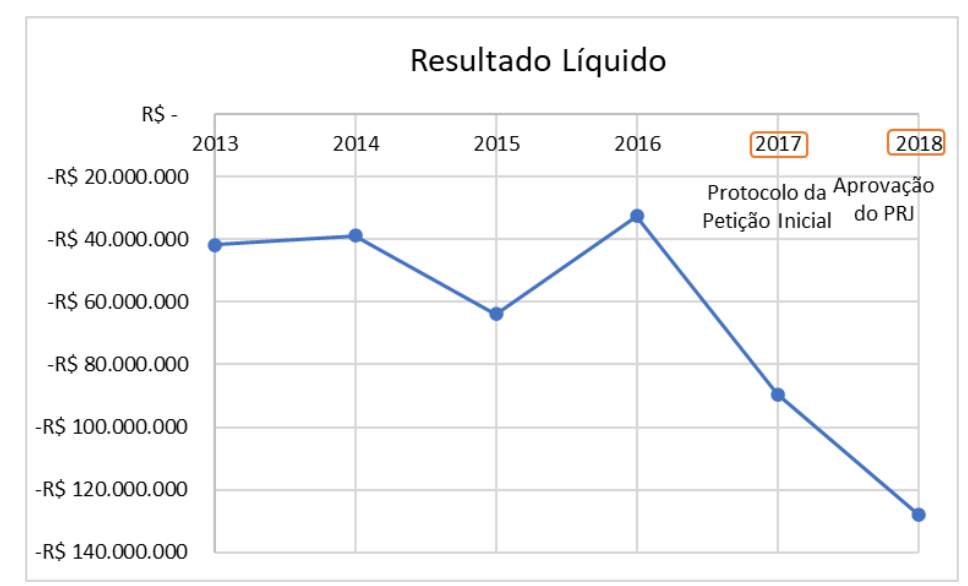

Figura 2. Brasil Supply S.A. Elaboração própria.

No ano de 2014, os prejuízos diminuíram 7,17\% em comparação ao ano de 2013. Já em 2015, houve aumento de 64,52\% em relação ao ano anterior. Em 2016, apesar da melhora de 48,93\% em comparação ao ano de 2015, ainda acumulou prejuízos. Em 2017, os prejuízos aumentaram em 174,71\% em relação ao ano de 2016. Em 2018, os resultados negativos aumentaram em 43,10\% em comparação ao ano de 2017. Desde 2013 até 2018 a sociedade acumulou prejuízos. O pior resultado da companhia ocorreu no exercício social da aprovação do plano de recuperação judicial. Os prejuízos foram acumulados durante todo o período processual anterior à aprovação do plano pelos credores. Deste modo, identifica-se uma aparente contradição na tomada de decisão dos credores, que optaram assumir o risco de um insucesso no cumprimento do plano, aprovando-o.

\subsubsection{Arpoador Engenharia Ltda.}

As informações de 2014, 2015 e 2016 foram coletadas das demonstrações contábeis em anexo a petição inicial. As demais foram obtidas pelos relatórios mensais. 


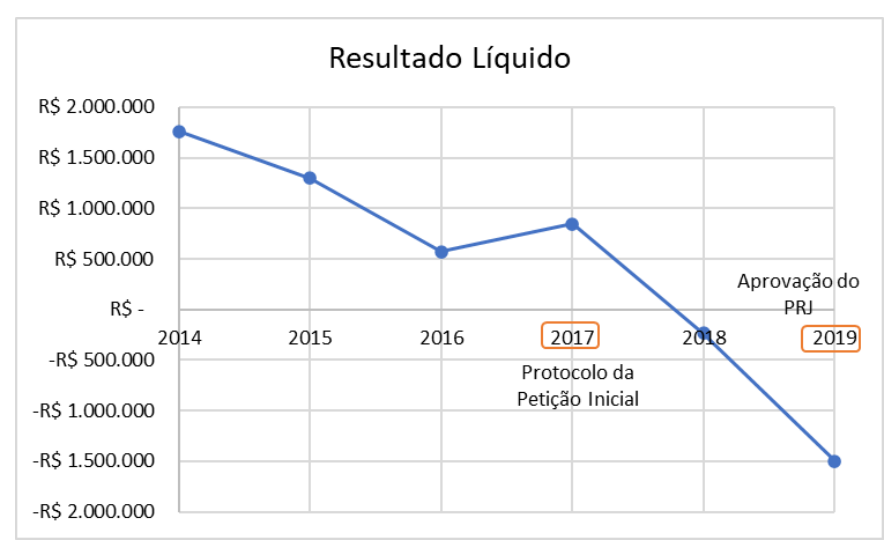

Figura 3. Arpoador Engenharia Ltda. Elaboração própria.

Em 2015, verifica-se a queda dos resultados líquidos em 26,43\% em comparação ao ano de 2014. Em 2016, os lucros reduziram novamente em 55,89\% em relação ao ano anterior. Em 2017, identifica-se aumento dos lucros de 48,33\% em relação ao ano de 2016. Em 2018, a sociedade passou a apresentar prejuízo com a queda dos resultados de 127,98\% em relação ao ano de 2017. Em 2019 houve aumento no prejuízo de 531,92\% em relação ao ano de 2018. O gráfico apresenta uma tendência de deterioração da atividade empresarial corroborada desde 2014. Em 2017, exercício social do ajuizamento da ação, houve uma leve melhora no resultado, mas passou a apurar prejuízos nos anos seguintes de 2018 e 2019 . O exercício da aprovação do plano de recuperação judicial pelos credores (2019) foi o pior entre os seis anos analisados. A despeito de toda esta involução, o plano de recuperação foi aprovado por todas as classes de credores representadas na assembleia.

\subsubsection{Companhia Federal de Fundição S.A.}

Os resultados líquidos da devedora apurados anos de 2015, 2016 e 2017 foram extraídos das demonstrações contábeis anexadas a petição inicial. As informações financeiras de 2018 e de 2019 foram obtidas nos relatórios mensais do administrador judicial. 


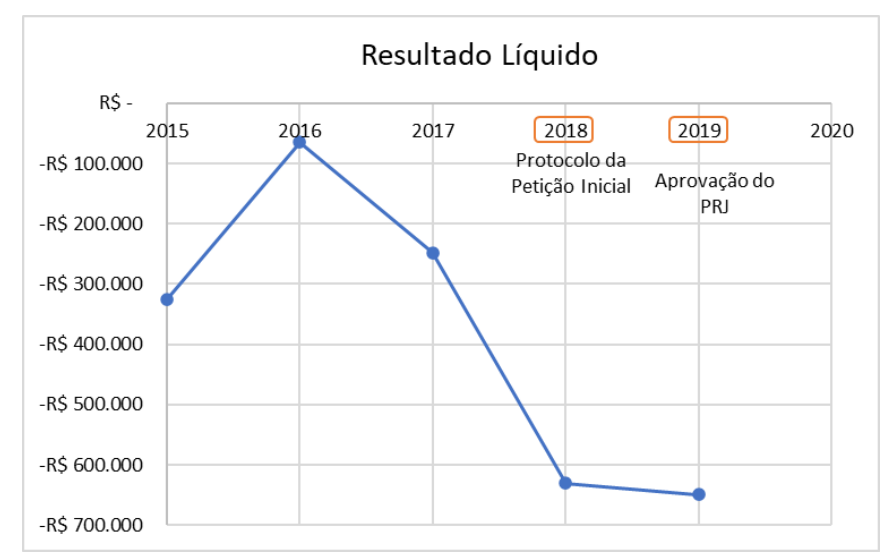

Figura 4. Companhia Federal de Fundição. Elaboração própria.

No ano de 2016, houve a melhora nos resultados de $80,07 \%$ em relação ao ano de 2015. Em 2017, houve aumento no prejuízo de 280,67\% em relação ao ano anterior. Em 2018, o prejuízo aumentou em 154,47\% em relação ao ano de 2017 e, em 2019, novamente o prejuízo cresceu em 3,03\% em comparação ao ano de 2018. Como se percebe pelo gráfico, a devedora acumulou prejuízos entre todos os exercícios sociais de 2015 a 2019. Em 2016, os resultados melhoraram, mas continuaram negativos. O gráfico também evidencia que os declínios dos resultados estancaram durante o período processual que antecedeu a aprovação do plano de recuperação pelos credores; porém, o exercício de 2019, ano da provação do plano, foi o pior dos cinco exercícios de análise. Ciente de toda esta situação pelos documentos aos quais tiveram acesso e esclarecimentos do administrador judicial, ainda assim os credores aprovaram o plano e a recuperação foi concedida.

\subsubsection{Hotéis Othon S.A.}

O gráfico foi preparado com a documentação de Hotéis Othon S.A. que instruiu a petição inicial, bem como pelas informações apresentadas pelo administrador judicial em seus relatórios mensais. 


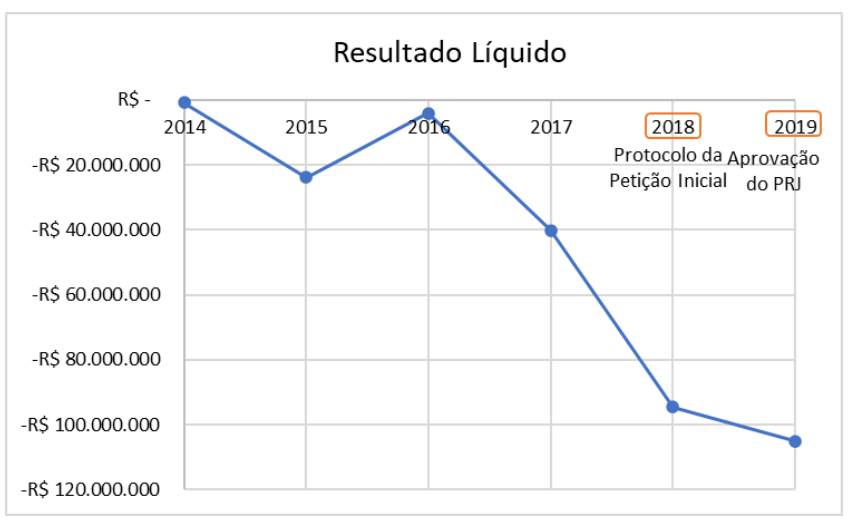

Figura 5. Hotéis Othon S.A. Elaboração própria.

Em 2015, houve um agravamento do prejuízo de 2.762,74\% em relação ao ano de 2014. Em 2016, o prejuízo reduziu em 82,27\% em relação ao ano anterior. Em 2017, houve a piora do prejuízo foi de 850,86\% em comparação ao ano de 2016. Em 2018, o prejuízo cresceu em 135,28\% em relação ao ano de 2017. Em 2019, houve aumento no prejuízo de 11,23\% em comparação ao ano de 2018. O gráfico apresenta uma tendência de aumento dos prejuízos a partir do exercício social de 2017. Nos exercícios de 2014 (Copa do Mundo) e 2016 (Jogos Olímpicos), conseguiu-se alcançar o ponto de equilíbrio entre receitas e despesas. Contudo, os prejuízos se acumularam acentuadamente até o exercício de 2019, último ano pesquisado. Entre o início do processo de recuperação judicial e a aprovação do plano, acumularam-se expressivos prejuízos, aumentando o grau de iliquidez da devedora. Contudo, este cenário não representou impedimento para a aprovação do plano, ainda que as incertezas no cenário econômico também não recomendassem a medida.

\subsection{Prazo médio entre a decisão de deferimento do processamento da recuperação judicial e a instalação da assembleia}

A LRF, art. 56, $\S 1^{\circ}$, determina que se houver objeção de qualquer credor ao plano de recuperação judicial, o juiz deverá convocar assembleia de credores para deliberar sobre a aprovação, rejeição ou modificação dele. A data da assembleia, termo final, designada na segunda convocação, não deve ultrapassar o prazo de 150 dias, contados do deferimento do processamento da recuperação judicial, termo inicial.

\begin{tabular}{|c|c|c|c|}
\hline AUTOR & $\begin{array}{c}\text { DEFERIMENTO DO } \\
\text { PROCESSAMENTO }\end{array}$ & $\begin{array}{c}\text { INSTALAÇÃO } \\
\text { DA AGC }\end{array}$ & PRAZO \\
\hline Civilport Engenharia LTDA. e outro & $21 / 10 / 2015$ & $14 / 10 / 2016$ & 359 \\
\hline
\end{tabular}




\begin{tabular}{|l|c|c|c|} 
Brasil Supply S.A. e outros & $23 / 02 / 2017$ & $22 / 02 / 2018$ & 364 \\
\hline Arpoador Engenharia LTDA. & $10 / 01 / 2018$ & $11 / 04 / 2019$ & 456 \\
\hline Companhia Federal de Fundição & $10 / 07 / 2018$ & $05 / 04 / 2019$ & 269 \\
\hline Hotéis Othon S.A. e outros & $28 / 11 / 2018$ & $22 / 11 / 2019$ & 359 \\
\hline
\end{tabular}

Apurou-se o tempo médio de 361 dias entre o deferimento do processamento das recuperações e instalação da assembleia, logo, acima do dobro do prazo previso em lei.

\subsection{Análise do comportamento dos credores na assembleia para aprovação do plano e suas eventuais alterações, por classe}

Também com apoio na jurimetria, analisou-se a votação dos credores por classe dos cinco processos que compõem a amostra da pesquisa.

a) Classe I - titulares de créditos derivados da legislação do trabalho ou decorrentes de acidentes de trabalho. Em apenas 3 dos 5 processos analisados, houve a formação de classe de credores trabalhistas (art. 41, I). Nestes processos, a aprovação ocorreu da seguinte forma:

- Civilport Engenharia Ltda. e outro(s), o plano obteve a aprovação pela unanimidade dos credores da classe I presentes à assembleia, na votação por cabeça.

- Companhia Federal de Fundição, o plano também obteve a aprovação pela unanimidade dos credores presentes.

- Hotéis Othon S.A. e outros, o plano alcançou a aprovação de 99,39\% dos credores da classe I presentes.

Não se identificou a participação de credores trabalhistas relacionados no processo de recuperação judicial da Brasil Supply S.A. e outros e no processo da sociedade Arpoador Engenharia Ltda (ata, 2019, p. 1.296 a 1.304).

Desse modo, identifica-se um massivo apoio dos credores trabalhistas ao plano de recuperação judicial nos três pocessos em que puderam expressar a vontade em assembleia, apesar das demosntrações financeiras evidenciarem uma difícil regeneração da crise da empresa. Da mesma forma, os trabalhadores não se insurgiram contra a morosidade processual. Pelo contrário, passados, em média, um ano do deferimento do processamento, concederam mais uma oportunidade para a devedora se revitalizar aprovando o plano com uma média de $99,79 \%$ dos credores. 
b) Classe II - titulares de créditos com garantia real. Em nenhum dos cinco processos se identificou credores relacionados na classe II, conforme descrito nas atas das assembleias: Civilport Engenharia Ltda. e outros (ata, 2016, p. 2.272 a 2.299); Brasil Supply S.A. e outros (ata, 2018, p. 7.802 a 7.837); Arpoador Engenharia Ltda. (ata, 2019, p. 1.296 a 1.304); Companhia Federal de Fundição. (ata, 2019, p. 1.572 a 1.599); Hotéis Othon S.A. e outros (ata, 2019, p. 1.5150 a 1.5197).

c) Classe III - titulares de créditos quirografários, com privilégio especial, com privilégio geral ou subordinados. Em todos os processos analisados houve participação de credores relacionados na classe III do art. 41 (quirografários, privilegiados e subordinados). Nesta classe, a aprovação do plano depende da observância do disposto no art. 45, § $3^{\circ}$ (a proposta deverá ser aceita por credores que representem mais da metade do valor total dos créditos presentes à assembleia e, cumulativamente, pela maioria simples dos credores presentes). Adotando-se tal premissa e com apoio na jurimetria, apresenta-se os percentuais de aprovação:

- Civilport Engenharia Ltda. e outro - 89,5\% dos credores, representativos de 74,1\% dos créditos, votaram a favor da aprovação do plano de recuperação judicial.

- Brasil Supply S.A. e outros - $100 \%$ dos credores presentes que representam a totalidade dos créditos da classe.

- Arpoador Engenharia Ltda. - 100\% dos credores presentes que representam a totalidade dos créditos da classe.

- Companhia Federal de Fundição S.A. - 65\% dos credores presentes, representantivos de $75,51 \%$ dos créditos presentes, votaram pela aprovação do plano de recuperação judicial

- Hotéis Othon S.A. e outro (s). - 94,55\% dos credores representativo de 80,33\% dos créditos presentes, votaram pela aprovação do plano de recuperação judicial.

Assim como na classe I, trabalhadores, os credores quirografários aprovaram o plano com ampla maioria. Em dois processou a adesão ao plano ocorreu por aclamação. Em média, $89,81 \%$ dos credores quirografários presentes na assembleia aprovaram o plano recuperacional. Estes credores representaram 85,98\% dos créditos quirografários no conclave. d) Classe IV - credores enquadrados como microempresa ou empresa de pequeno porte. Não se identificou credores desta classe no processo (ata, 2019, p. 1.296 a 1.304). Nos demais processos, os credores votaram pela aprovação do plano da seguinte forma: 
- Civilport Engenharia Ltda. e outro - 95,1\% dos credores presentes a favor da aprovação do plano de recuperação judicial.

- Brasil Supply S.A. e outros - $100 \%$ de aprovação pelos credores de Brasil Supply e de BS Fluidos Ltda.; 95,3\% pelos credores de BSCO Navegação S.A. pela aprovação do plano de recuperação judicial.

- Companhia Federal de Fundição - obteve $80 \%$ dos credores pela aprovação do plano de recuperação judicial.

- Hotéis Othon S.A. e outros - 100\% dos credores presentes.

$\mathrm{O}$ apoio dos credores relacionados na classe IV à recuperação da empresa em crise não foi menor do que nas demais classes. Pelo contrário, novamente, em dois processos houve aprovação por aclamação. A média dos credores relacionados na classe IV que aprovaram os planos alcançou 94,08\%.

\subsubsection{Análise da decisão do credor em assembleia}

Credores de diferentes perfis, por exemplo, trabalhistas e quirografários, aprovaram o plano de recuperação judicial das cinco sociedades empresárias, não obstante a análise gráfica dos resultados líquidos evidenciarem, à época da assembleia, uma tendência de agravamento da crise. Logo, havia pouca probabilidade de revitalização da atividade empresária e da recuperação de seus créditos e o cenário sugeria que o melhor fosse a rejeição do plano. A média dos credores nas classes I, III e IV que aprovaram os planos atingiu 94,5\% dos presentes em assembleia. Não houve expressiva variação entre as classes, pelo contrário. A classe de maior adesão, classe I, somou 99,7\% dos credores e a classe com menor apoio, classe III, obteve $89,8 \%$ dos credores. Logo, uma diferença de apenas 10\%, que é inexpressiva. O respeito à vontade do credor nos casos estudados não deve ser desprezado. A racionalidade do voto, aparentemente de difícil compreensão, deve ser interpretada ante a maximização do bem-estar social e busca da felicidade, que se baseia na crença de que o plano poderá ser capaz de proporcionar a superação da crise ao invés da falência.

\section{CONCLUSÃO}


Ao aplicar as técnicas de jurimetria ao processo de recuperação judicial para se aferir a arquitetura decisória dos credores em assembleia, constata-se que houve uma maximização da felicidade do credor, visto que a ampla maioria deles, 94,5\%, aprovou os planos apresentados pelas devedora. Desse modo, atende-se aos ideais da Teoria do Direito com base no Utilitarismo e na maximização da felicidade, entendida na recuperação como a satisfação do crédito, ainda que em prazo e condições desfavoráveis..

Da mesma forma, a tomada de decisão dos credores teria satisfeito a concepção Consequencialista do Direito. Os credores tiveram acesso aos documentos que permitiriam analisar as diferentes alternativas e consequências de seus votos. Acrescenta-se que credores de diferentes perfis votaram de forma uníssona, como no caso dos trabalhistas e quirografários.

A eficiência do voto do credor analisada pela perspectiva da Análise Econômica do Direito deve ser pesquisada com maior profundidade, pois a promoção da eficiência do Direito aferida pela maximização do bem-estar social é de difícil percepção nos cinco casos estudados.

Pelas análises gráficas, as sociedades empresárias dificilmente conseguirão se soerguer devido a tendência de agravamento da crise de liquidez. Logo, os credores teriam maiores dificuldades de obtenção de seus créditos, quiçá impossibilidade.

$\mathrm{Na}$ mesma linha, a jurimetria demosntrou que os procesos não tramitaram de forma célere. Pelo contrário, as análises demosntraram que o período entre o deferimento do processamento da recuperação e a instalação da assembleia, em média, foi de 1 ano. O tempo é o dobro do prazo de até 180 dias determinado pela Lei $\mathrm{n}^{\circ} 11.101 / 2005$. Diante desta morosidade, as despesas dos credores aumentam sensivelmente e não podem ser reclamadas no processo de recuperação (art. $5^{\circ}$, II), o que prejudica o bem-estar social deles.

Nao obstante os cenários de agravamento das crises e das lentidões processuais, os credores apoiaram as cinco recuperações judiciais, o que seria contraditório numa análise puramente racional.

Considerando a adesão maciça dos credores ao plano apresentado pelas devedoras, novas pesquisas devem ser desenvolvidas para se compreender as razões que motivaram o voto. Eventuais custos de transação (consumir mais recursos com baixa perspectiva de retorno) ou de oportunidade (evitar a falência que poderia diminuir ainda mais o bem-estar social) podem ter influenciado na decisão. 


\section{REFERÊNCIAS}

FUX, Luiz. Processo civil \& análise econômica. Rio de Janeiro: Forense, 2019.

LEAL, Fernando; PINHEIRO, Armando Castelar (coord.). Direito e economia: diálogos. Rio de Janeiro: FGV Editora, 2019.

GUIMARÃES, Márcio de Souza. Direito das empresas em dificuldades. In. PINHEIRO, Armando Castelar; PORTO, Antônio J. Maristrello; SAMPAIO Patrícia Regina Pinheiro (coord.) Direito e Economia Diálogos. Rio de Janeiro: FGV Editora, 2019.

POSNER, Richard A. Economic Analysis of Law. $7^{\text {th }}$ ed. Chicago; New York: Wolters Kluwer, 2007.

RIO DE JANEIRO. Tribunal de Justiça. Comarca da Capital. 6 $6^{\mathrm{a}}$ Vara Empresarial da Comarca da Capital. Processo n. ${ }^{\circ}$ 0409623-93.2015.8.19.0001. Autor: Civilport Engenharia LTDA. e outros. Juiz de Direito Maria Cristina de Brito Lima. Rio de Janeiro, 2018.

RIO DE JANEIRO. Tribunal de Justiça. Comarca da Capital. 5 $5^{\text {a }}$ Vara Empresarial. Processo: 0040930-62.2017.8.19.0001. Autor: Brasil Supply S.A. e Outros. Juíza de Direito Maria da Penha Nobre Mauro. Rio de Janeiro, 2017.

RIO DE JANEIRO. Tribunal de Justiça. Comarca da Capital. $1^{\text {a }}$ Vara Empresarial. Processo: 0310724-89.2017.8.19.0001. Autor: Arpoador Engenharia Ltda. Juiz de Direito Alexandre Mesquita. Rio de Janeiro, 2017.

RIO DE JANEIRO. Tribunal de Justiça. Comarca da Capital. $4^{\mathrm{a}}$ Vara Empresarial. Processo: 0141112-22.2018.8.19.0001. Autor: Companhia Federal de Fundição. Juiz de Direito Paulo Assed Estefan. Rio de Janeiro, 2018.

RIO DE JANEIRO. Tribunal de Justiça. Comarca da Capital. 5 ${ }^{\text {a }}$ Vara Empresarial. Processo: 0280230-13.2018.8.19.0001. Autor: Hotéis Othon S.A. e outros. Juíza de Direito Maria da Penha Nobre Mauro. Rio de Janeiro, 2018.

SCALZILLI, João Pedro; SPINELLI, Luis Felipe; TELLECHEA, Rodrigo. Recuperação de Empresas e Falência Teoria e Prática na Lei 11.101/2005. 3 ed. São Paulo: Almedina, 2018. 